\title{
Longitudinal Assessment of Neuroradiologic Features in Wolfram Syndrome
}

\author{
(D) A. Samara, (D) H.M. Lugar, (D)T. Hershey, and (D).S. Shimony
}

\begin{abstract}
BACKGROUND AND PURPOSE: Wolfram syndrome is a rare genetic disease with characteristic brain involvement. We reviewed the brain MR images of patients with Wolfram syndrome to determine the frequency and characteristics of common neuroradiologic findings.

MATERIALS AND METHODS: We retrospectively reviewed the imaging data of patients with genetically-confirmed Wolfram syndrome who had been recruited to the Washington University Wolfram Syndrome Research Clinic. These patients were evaluated between 2010 and 2019 with annual MRIs, along with other measures. MR images were assessed for clinical neuroradiologic signs at each individual's first and last follow-up visits to characterize the frequency, rate of progression, and clinical correlations of these signs.

RESULTS: We included 30 patients (13 males/17 females; average age at first visit, 14 years; average age at last visit, 19 years). The median duration of follow-up was 5 years (range, 2-9 years). The most common findings were an absent or diminished posterior pituitary bright spot (first, 53\%; last, 70\%), T1/T2 pons signal abnormalities (first, 53\%; last, 67\%), optic nerve atrophy (first, 30\%; last, 80\%), white matter T2 hyperintensities (first, 27\%; last, 35\%), and cerebellar atrophy (first, 23\%; last, $70 \%$ ).

CONCLUSIONS: Patients with Wolfram syndrome present characteristic neuroradiologic findings that involve the posterior pituitary gland, optic nerves, white matter, brain stem, and cerebellum. These abnormal findings appear at an early age and tend to increase in frequency with time. However, the neurologic significance and neuropathologic mechanisms of each sign require more investigation. Neuroradiologists should be aware of the pattern of these features in Wolfram syndrome.
\end{abstract}

ABBREVIATIONS: $\mathrm{DI}=$ diabetes insipidus; PPBS = posterior pituitary bright spot

W olfram syndrome is a rare genetic multisystem disease characterized by juvenile-onset diabetes mellitus, progressive optic atrophy, sensorineural hearing loss, and diabetes insipidus (DI). Two clinical variants of Wolfram syndrome result from wolframin ER transmembrane glycoprotein (WFS1) and CDGSH iron sulfur domain 2 (CISD2) (WFS2) mutations. ${ }^{1,2}$ The pathophysiology

Received June 26, 2020; accepted after revision August 6.

From the Departments of Psychiatry (A.S., H.M.L.) and Neurology (T.H.) and Mallinckrodt Institute of Radiology (T.H., J.S.S.), Washington University School of Medicine, St. Louis, Missouri.

The research reported in this publication was supported by National Institute on Drug Abuse grant Nos. 5T32DA007261-27, HD070855 (T. Hershey, Principal Investigator), U54 HD087011 (Intellectual and Developmental Disabilities Research Center at Washington University), UL1 RR024992 (Clinical and Translational Science Awards), DK020579 (Diabetes Research Center); the George Decker and Julio V. Santiago Pediatric Diabetes Research Fund; the Snow Foundation; the American Diabetes Association; Mallinckrodt Institute of Radiology; and the McDonnell Center for Systems Neuroscience.

Please address correspondence to Tamara Hershey, PhD, Mallinckrodt Institute of Radiology, Washington University School of Medicine, 4525 Scott Ave, St. Louis, MO 63110; e-mail: tammy@wustl.edu

- Indicates open access to non-subscribers at www.ajnr.org

http://dx.doi.org/10.3174/ajnr.A6831 of Wolfram syndrome is attributed to multiple etiologies, including increased endoplasmic reticulum stress, calcium homeostasis disturbances, and primary or downstream mitochondrial dysfunction. ${ }^{3-5}$ Previous studies have shown that Wolfram syndrome is associated with structural brain changes and multiple neurologic symptoms, eg, bladder dysfunction, gait and balance abnormalities, and loss of smell and taste sensations. ${ }^{6-9}$ The pathophysiologic mechanisms underlying these neurologic manifestations are an area of active research.

Convergent evidence derived from histopathologic and quantitative neuroimaging studies indicates that Wolfram syndromerelated structural brain changes comprise a combination of early developmental hypomyelination and late neurodegeneration. ${ }^{10-12}$ Neuroradiologic findings previously reported in Wolfram syndrome include marked brain stem and cerebellar atrophy, optic nerve and optic tract atrophy, and an absent posterior pituitary bright spot on T1-weighted MR images. ${ }^{13-15}$ However, this work has been limited by small cohorts of patients with advanced disease, did not include longitudinal follow-up, ${ }^{13,14}$ and was typically conducted before the age of genetic testing for Wolfram syndrome. ${ }^{15}$ To better define the range and progress of neuroradiologic signs in 
Wolfram syndrome, we evaluated the evolution of clinical neuroradiologic findings across time in a genetically-confirmed group of children, adolescents, and young adults with Wolfram syndrome.

\section{MATERIALS AND METHODS Study Population}

Data from participants in the Washington University Wolfram Syndrome Research Clinic were evaluated. Patients were enrolled between January 2010 and December 2019. Inclusion criteria were genetically-confirmed Wolfram syndrome (WFS1 mutations on both alleles that are known or suspected to be pathogenic), participant's awareness of the diagnosis, age younger than 30 years at the time of enrollment, and the ability to travel to St. Louis for the annual research clinic visits. We have previously reported aspects of the clinical and imaging data from subsets of this cohort. ${ }^{7,8,10,11,16-18}$

\section{MR Imaging Review}

A single 3T Tim Trio scanner (Siemens) was used in 2010-2018, and a single 3T Magnetom Prisma scanner (Siemens) was used for 2019. Each scanning session included 3D T1-weighted sequences. For the Tim Trio, the T1-weighted MPRAGE sequence was used (sagittal acquisition: $\mathrm{TR}=2400 \mathrm{~ms}, \mathrm{TE}=3.16 \mathrm{~ms}, \mathrm{TI}=1000 \mathrm{~ms}$, voxel resolution $=1 \times 1 \times 1 \mathrm{~mm}$, time $=8$ minutes and 9 seconds).

Table 1: The demographic and clinical characteristics in patients with Wolfram syndrome at first and last follow-up visits $^{2}$

\begin{tabular}{lcc}
\hline & First Visit $(\boldsymbol{n}=\mathbf{3 0})$ & Last Visit $(\boldsymbol{n}=\mathbf{3 0})$ \\
\hline Age (yr) & $14 \pm 6$ & $19 \pm 6$ \\
Duration of disease $(\mathrm{yr})$ & $3 \pm 3$ & $8 \pm 4$ \\
Diabetes mellitus & $29(97)$ & $30(100)$ \\
Vision impairment & $28(93)$ & $28(93)$ \\
Hearing loss & $20(67)$ & $23(77)$ \\
Diabetes insipidus & $15(50)$ & $19(63)$ \\
Bladder dysfunction & $13(43)$ & $26(86)$ \\
\hline
\end{tabular}

${ }^{a}$ For the age and duration of disease, means and SDs are reported. For comorbid conditions, numbers and percentages are reported.
On the Magnetom Prisma scanner, the MPRAGE sequence was slightly different $(\mathrm{TR}=2500 \mathrm{~ms}, \mathrm{TE} 1=1.81 \mathrm{~ms}, \mathrm{TE} 2=3.6 \mathrm{~ms}$, $\mathrm{TE} 3=5.39$ and $7.18 \mathrm{~ms}, \mathrm{TI}=1000 \mathrm{~ms}$, voxel resolution $=0.8 \times$ $0.8 \times 0.8 \mathrm{~mm}$, maximum acquisition time $=8$ minutes and $22 \mathrm{sec}-$ onds). FLAIR was acquired on the Tim Trio scanner before 2019. The FLAIR sequence had the following parameters: transverse acquisition $-\mathrm{TR}=9190 \mathrm{~ms}, \mathrm{TE}=98 \mathrm{~ms}, \mathrm{TI}=2500 \mathrm{~ms}$, flip angle $=$ $150^{\circ}$, voxel resolution $=0.9 \times 0.9 \times 3 \mathrm{~mm}$, time $=3$ minutes and 59 seconds. Resting-state blood oxygen level-dependent and diffusion-weighted scans were also acquired but are not reported in this publication.

On the basis of prior studies, ${ }^{13-15,19}$ we focused our review on 6 neuroradiologic signs: 1) a negative posterior pituitary bright spot (PPBS) seen on T1-weighted images, midline sagittal view; 2) T1/ $\mathrm{T} 2$ pons signal abnormalities, defined as $\mathrm{T} 1$ hypointensity and T2 hyperintensity on midline sagittal views; 3) optic nerve atrophy and optic chiasm thinning evaluated on coronal sections at the level of optic chiasm; 4) white matter T2 hyperintensity on FLAIR images; 5) cerebellar atrophy; and 6) brain stem atrophy.

One neuroimaging researcher with 3 years of experience (A.S.) and a board-certified neuroradiologist with $>20$ years of experience (J.S.S.) reviewed MRIs at each individual's first and last visit between 2010 and 2019. Because T2-weighted or FLAIR images were not collected in 2019, scans from the most recent visit before 2019 were used instead.

Each neuroradiologic sign was described categorically: "yes" if present, "no" if not present for all except the PPBS sign. The PPBS sign was categorized as "present," "diminished," or "absent," and the last 2 assignments were combined to indicate a negative PPBS sign. When the 2 readings were different, the final decision for which reading would be used in the analysis was made through consensus.

\section{Statistical Analysis}

Statistical analyses were conducted using R statistical and computing software (Version 3.6.3; http://www.r-project.org/). For the 6 most common findings, interrater reliability $(\kappa)$ was calculated $^{20}$ and categorized as poor $(<0.21)$, fair $(0.21-0.40)$, moderate (0.41-0.60), substantial $(0.61-0.80)$, or almost perfect $(>0.80) .^{21} \chi^{2}$ tests were used to compare the frequency distributions between the first and last visits, and Mann-Whitney $U$ tests were used to compare the median number of neuroradiologic signs at first and last visits. The Spearman's $\rho$ was used to determine whether age and the total number of neuroradiologic signs were linearly associated. The significance level was set at a $P<.05$.

\section{RESULTS}

\section{Patient Characteristics}

MRIs from 30 patients (13 males/17 females) with at least $2 \mathrm{MR}$ imaging sessions were evaluated. Scans were
FIG 1. Sagittal, coronal, and axial MR images show pons signal abnormalities as T1 hypointensity and $\mathrm{T} 2$ hyperintensity in a patient with Wolfram syndrome (white arrows). Brain stem atrophy is also evident on this MR image. 


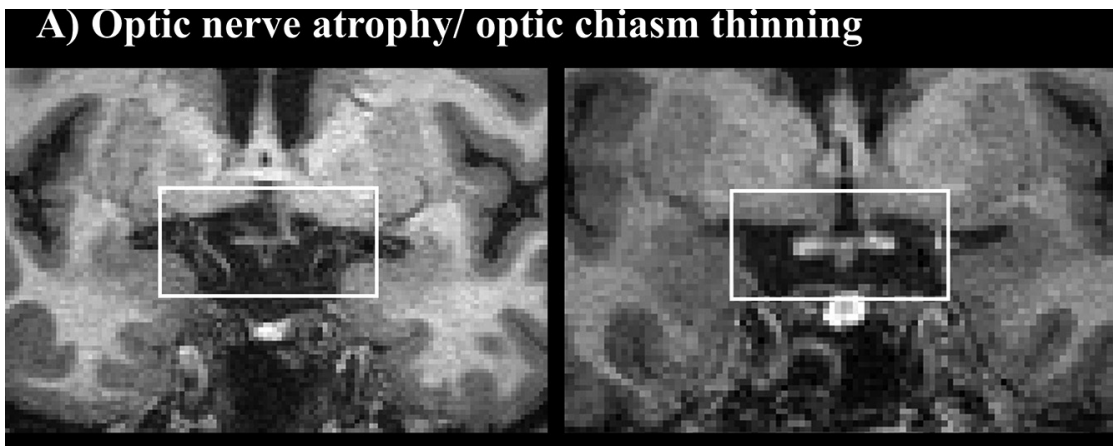

\section{B) Absent or diminished posterior pituitary bright spot}
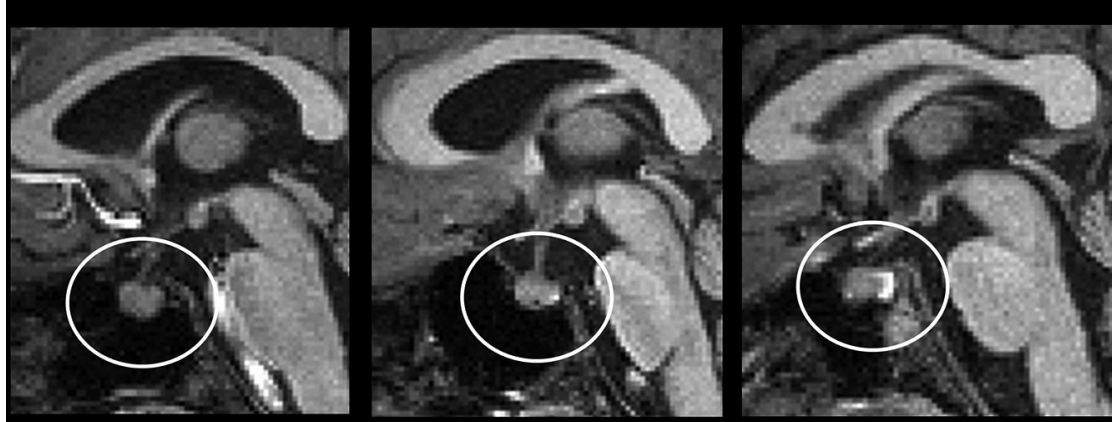

C) White matter T2 hyperintensities

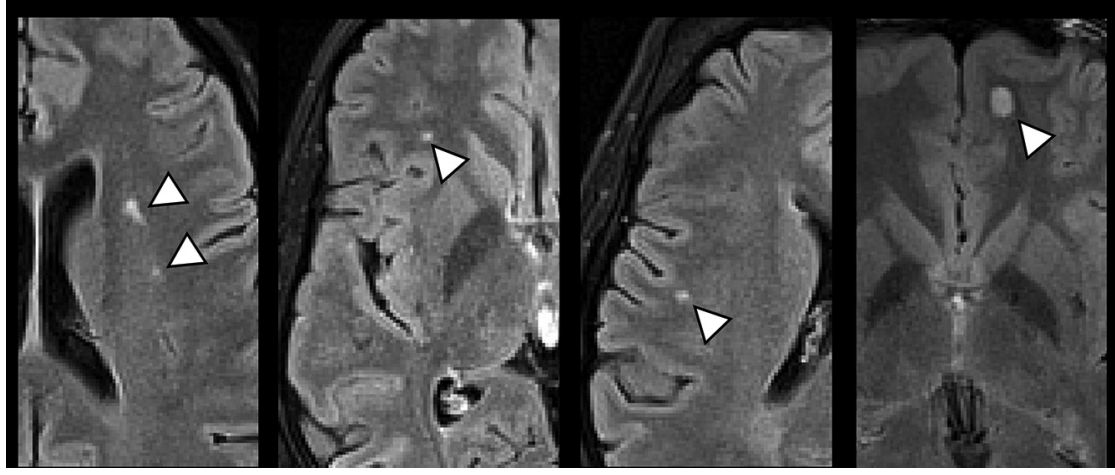

FIG 2. Examples of neuroradiologic findings in patients with Wolfram syndrome. A, Thinning of the optic chiasm (white box) as seen in coronal T7-weighted images (left, patient with Wolfram syndrome; right, healthy control). B, Abnormal PPBS signal (white circles) in midline sagittal T1weighted images (from left to right, absent, diminished, and physiologic signal). $C$, White matter hyperintensities in FLAIR MR imaging (white arrowheads).

between 2 and 9 years apart (median, 5 years). Demographics and clinical features at each session are in found in Table 1.

\section{Neuroradiologic Findings}

Interrater reliability ranged between fair and almost perfect: optic nerve atrophy $(\kappa=0.8)$, negative PPBS $(\kappa=0.79)$, cerebellar atrophy $(\kappa=0.83)$, pons signal change $(\kappa=0.42)$, white matter hyperintensity $(\kappa=0.58)$, and brain stem atrophy $(\kappa=0.37)$. See Figs 1-3 for examples of neuroradiologic signs and Table 2 for the frequency of these signs in patients at first and last scanning. Because of the low interrater reliability in evaluating brain stem atrophy, we excluded this sign from subsequent statistical analyses. However, a previous quantitative analysis of brain stem atrophy in a subset of our cohort revealed a $27 \%$ difference in volume compared with controls and a mean estimated annual percentage rate of change of $-0.85 \% .^{10,18}$

At the first visit, the most common neuroradiologic findings were a negative PPBS sign and T1/T2 pons signal abnormalities, followed by optic nerve atrophy, white matter T2 hyperintensities, and cerebellar atrophy. In all cases, the signs observed in the first visit were either stable or increased on follow-up scans. Optic nerve and cerebellar atrophy showed the most progression across time with a $160 \%-200 \%$ increase in prevalence between the first and last visits $(P<.001$ for both). On the other hand, white matter T2 hyperintensities seemed to be a relatively stable sign, with only a $25 \%$ increase in prevalence between the first and last visits $(P=$ .51). Overall, patients had a median of 2 and 3 neuroradiologic signs at the first and the last visits, respectively (paired Wilcoxon test, $P<.001$ ). About $80 \%$ of patients had at least 1 neuroradiologic sign at the first visit, and $100 \%$ had at least 1 sign at the last visit (Fig 4A). Longer duration of follow-up was associated with a greater increase in the number of neuroradiologic signs (Spearman's $\rho=0.47, P=.008)$.

\section{Relationship between Neuroradiologic Findings and Clinical Variables}

Older age was associated with a higher number of neuroradiologic signs at both visits (Spearman's $\rho$ : first $=0.53$, last $=0.55, P<.01$; Fig $4 B)$. The median number of signs was not different between males and females at both follow-up visits (MannWhitney $U$ test: first, $P=0.79$; last, $P=0.77$, respectively). There were no differences in sex ratios for each sign.

The positive/negative PPBS sign was not associated with the presence/absence of DI ( $\chi^{2}$; first: $P=.27$; last: $\left.P=.32\right)$. The sensitivity and specificity of the PPBS sign in predicting the DI diagnosis was $75 \%$ and $60 \%$ for the first visit and $79 \%$ and $45 \%$ for the last visit. The absence of the PPBS sign was not predictive of a future DI diagnosis during the follow-up period. Finally, there was no difference in mean best-corrected visual acuity (Logarithm of the Minimum Angle of Resolution) between normal-appearing and radiologically identified optic 

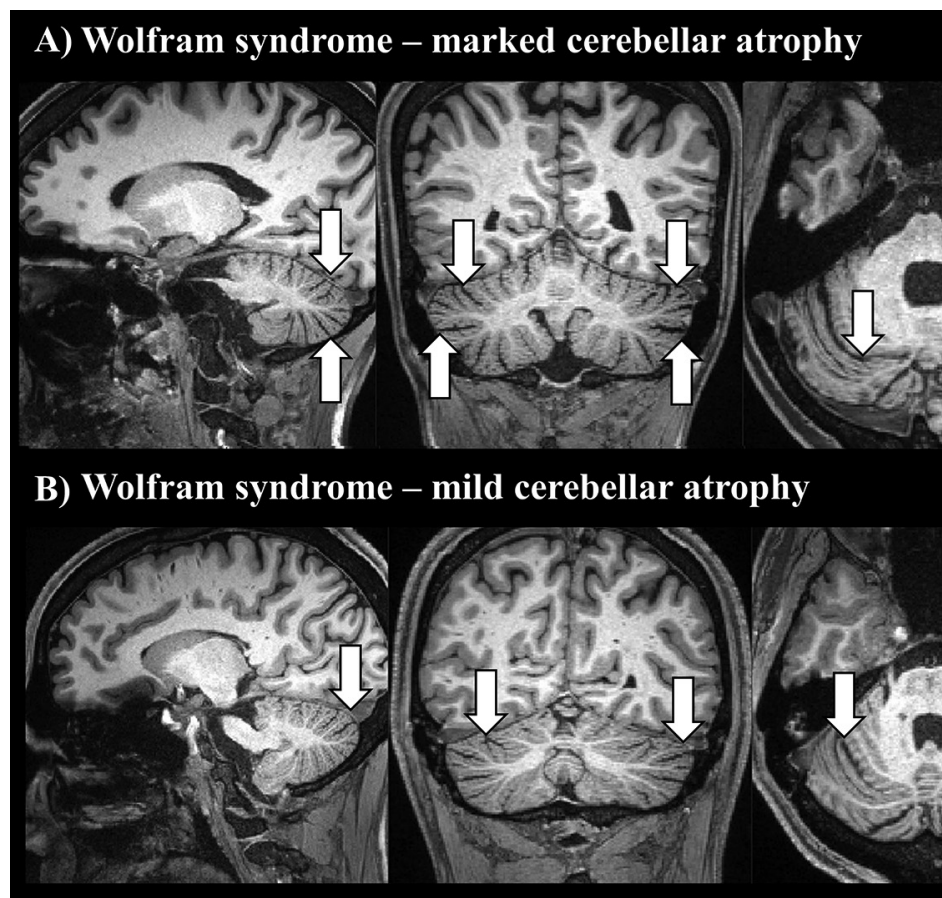

\section{rophy}

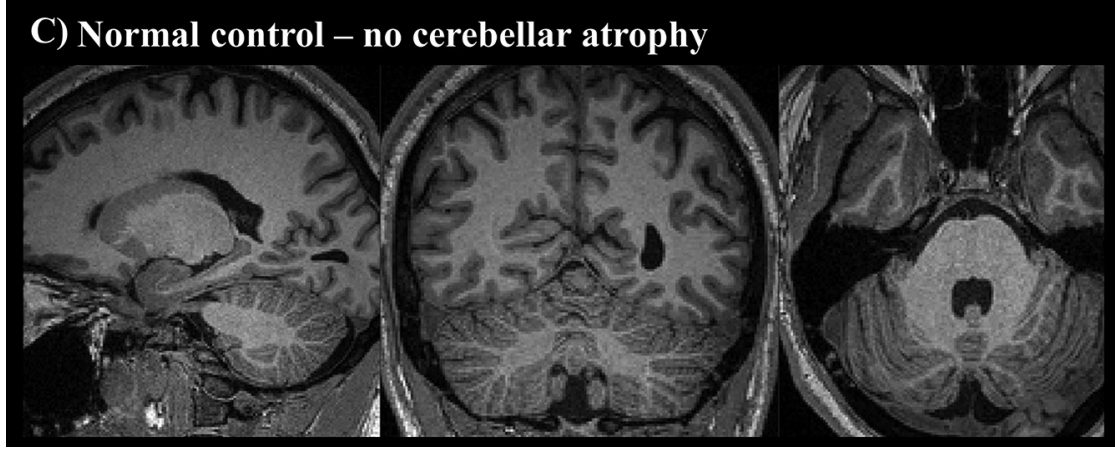

FIG 3. Marked $(A)$ and mild $(B)$ cerebellar atrophy in patients with Wolfram syndrome, as shown in sagittal, coronal, and axial T7-weighted MR images (white arrows), compared with a healthy control (C).

Table 2: Neuroradiologic findings in brain MR images in patients with Wolfram syndrome ${ }^{\mathrm{a}}$

\begin{tabular}{lcc}
\hline \multicolumn{1}{c}{ Radiologic Sign } & First Visit $(\boldsymbol{n}=\mathbf{3 0})$ & Last Visit $(\boldsymbol{n}=\mathbf{3 0})$ \\
\hline Negative PPBS sign & $16(53)$ & $21(70)$ \\
T1/T2 pons signal abnormalities & $16(53)$ & $20(67)$ \\
Optic nerve atrophy $^{\mathrm{b}}$ & $9(30)$ & $24(80)^{\mathrm{c}}$ \\
White matter T2 hyperintensities $^{\mathrm{d}}$ & $8(27)$ & $10(33)$ \\
Cerebellum atrophy $^{\mathrm{c}}$ & $7(23)$ & $21(70)^{\mathrm{c}}$ \\
\hline
\end{tabular}

${ }^{a}$ Numbers and percentages are reported.

${ }^{\mathrm{b}}$ Absent and diminished PPBS sign.

${ }^{c} P$ value $<.01$ ( $\chi^{2}$ test $)$.

${ }^{d}$ FLAIR images were not available to evaluate white matter T2 hyperintensity for 1 scan, and T2-weighted images were used instead.

nerve atrophy (Mann-Whitney $U$ test; first: $P=.09$, and last: $P=.48)$.

\section{DISCUSSION}

We describe the neuroradiology findings in a cohort of patients with well-characterized and genetically-confirmed Wolfram

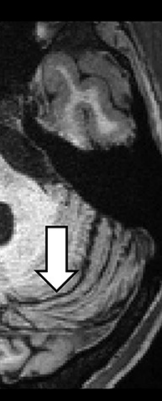

syndrome with longitudinal follow-up. The most common findings were a negative PPBS sign, T1/T2 pons signal abnormalities, optic nerve atrophy, white matter T2 hyperintensities, and cerebellar atrophy. The prevalence of these findings was higher in older patients and increased with time within individuals, suggesting that the accumulation of these signs reflects the evolution of neurodegenerative processes in this disease.

Overall, the most common neuroradiologic sign noticed in our cohort was a negative PPBS sign. Typically, the PPBS appears as a region of T1weighted hyperintensity in the posterior portion of the sella turcica. The nature of this signal has been controversial, and the exact substance responsible for the T1-shortening is not known. ${ }^{22}$ Changes in the appearance of the PPBS have been linked to the functional state of the pituitary gland, the neurosecretory granules containing the antidiuretic hormone (vasopressin), and the phospholipid component of the vesicles. ${ }^{23,24}$ A negative PPBS sign is observed in scans of healthy individuals in about $4 \%$ of the adult population ${ }^{25}$ but is more prevalent in most cases of primary and secondary central DI. ${ }^{26}$ One study has also shown that a preoperative negative PPBS sign was a predictor for postoperative DI development in cases of pituitary adenoma. ${ }^{27}$ The PPBS sign was also previously described in a case report of Wolfram syndrome. ${ }^{28}$ In our cohort, although the negative PPBS sign was twice as prevalent in the DI group compared with the non-DI group, the presence of this sign was not a significant predictor of the diagnosis because half of the individuals without DI also showed this sign.

The T1/T2 pons signal abnormalities observed in our cohort are rarely mentioned in the Wolfram syndrome imaging literature. Only 1 case report described similar pons signal changes in a patient with Wolfram syndrome. ${ }^{19}$ The location of the pontine signal change appears to overlap with the pontine nuclei and pontocerebellar white matter fibers. ${ }^{29}$ Because of its unique appearance and location in an area susceptible to imaging artifacts, this sign might have been previously missed and so under-reported in the literature. On the other hand, visual inspection of brain stem atrophy seems unreliable and less sensitive than quantitative analyses. 

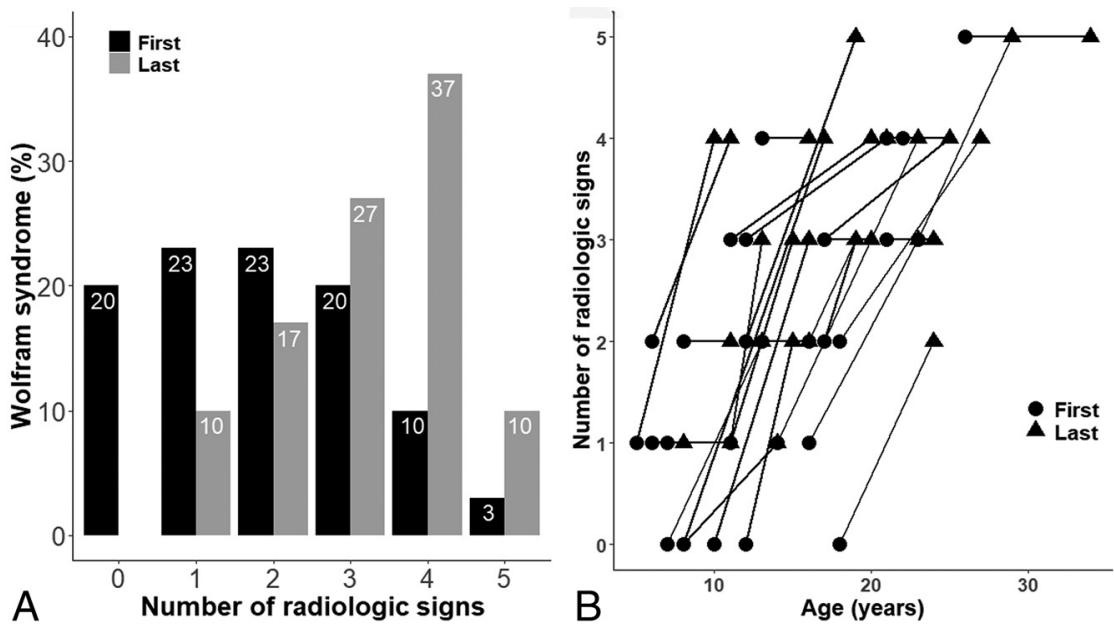

FIG 4. A, Frequency of neuroradiologic signs in patients with Wolfram syndrome at first and last visits. $B$, The relationship between age and the number of neuroradiologic signs. A line connecting a circle-shaped point (first visit) and a triangle-shaped point (last visit) represents each patient.

insignificant T2 hyperintensities. ${ }^{37}$ The radiologic appearance of these white matter T2 signal hyperintensities suggests possible demyelination, gliosis, or an inflammatory process. Previous histopathologic studies showed patchy demyelination and axonal degeneration in several white matter tracts in Wolfram syndrome, eg, the optic radiation and the pontocerebellar and corticopontine tracts. ${ }^{31-33}$ In prior work by our group, we evaluated white matter microstructure in Wolfram syndrome using diffusion tensor imaging. $8,10,11$ These quantitative analyses revealed that patients with Wolfram syndrome had widespread lower fractional anisotropy (reflecting decreased integrity of axon bundles) and higher radial diffusivity (reflecting impaired myelination) compared with age-equivalent controls.

However, quantitative evaluation of brain stem atrophy would require advanced segmentation software not available in all clinical settings. ${ }^{8,11}$ T1/T2 pons signal abnormalities may be more easily captured by visual inspection and appeared concurrently or sometimes preceded the development of brain stem atrophy detectable visually. Most interesting, although we did not include brain stem atrophy in the statistical analyses due to low interrater agreement, the cerebellum and brain stem atrophy observed in our cohort cooccurred at a high rate. Embryologically, these structures form together and are tightly linked. ${ }^{30}$ In patients with Wolfram syndrome, postmortem histologic examination of both the brain stem and cerebellum showed evidence of neuronal loss and gliosis in most brain stem nuclei. ${ }^{31-33}$ In the same studies, the cerebellum showed microscopic evidence of variable neuronal loss in the dentate nuclei and variable reduction of Purkinje cells of the cerebellum. ${ }^{31-33}$

The visual system is severely affected in Wolfram syndrome, as shown by previous histologic and neuroimaging studies. ${ }^{8,10,11,31-33}$ The optic nerves and optic chiasm were grossly atrophic with a prominent perioptic CSF space. The optic nerve atrophy in Wolfram syndrome may be related to retinal dysfunction and degeneration. ${ }^{34}$ This finding was evident as early as the first decade of life in our cohort. Histologic examination also reflects this dramatic change with multiple studies reporting optic nerve axonal degeneration associated with marked loss of myelinated axons and gliosis. ${ }^{31-33}$ Furthermore, previous work from our group has also shown that this damage is progressive, involves both pregeniculate and postgeniculate regions of the visual pathway, and correlates with the decline in visual function. ${ }^{35}$ Although the degree of visual system structure-function relationships is better evaluated via quantitative analyses, visual inspection of clinical scans captured the progressive nature of the visual pathway damage.

The presence of white matter lesions in Wolfram syndrome has been previously reported. ${ }^{36}$ The white matter hyperintensities appeared as small round or oval lesions mainly in the frontal and parietal white matter with no confluent lesions. The frequency of this finding exceeds what might be considered incidental clinically
Given that this finding was observed as early as 10 years of age in our cohort and was also relatively stable across time, it may be a neurodevelopmental process that occurs in the early stages of the disease. $^{8,12}$

Finally, previous studies have reported some neuroradiologic features in patients with Wolfram syndrome that we did not observe in our cohort. These include cortical malformations, diffuse white matter leukoencephalopathy, ${ }^{38}$ and high signal on proton-density and T2-weighted images in the substantia nigra. ${ }^{39}$

\section{CONCLUSIONS}

Our study describes the primary neuroradiologic features observed on MR imaging in Wolfram syndrome. The most common findings involved the posterior pituitary gland, optic nerve and optic chiasm, cerebral white matter, brain stem, and cerebellum. One strength of our study is that it includes a large cohort of patients with genetically-confirmed Wolfram syndrome with longitudinal follow-up from an early age. We also showed the rate of progression of these findings and their relation to demographic variables. However, our study was also limited by the lack of an explicit control group and the different sequences used for both the first and last visits.

Neuroradiologists should be aware of these findings when reading MR imaging studies of patients with Wolfram syndrome. Future research could pursue the diagnostic and prognostic value of these signs when combined with quantitative neuroimaging data and the pathophysiologic processes underlying these signs.

\section{ACKNOWLEDGMENTS}

We thank all of the participants at the Washington University Wolfram Research Clinic and their families for their time and effort and the Washington University Wolfram Research Clinic study staff for their dedication. We also thank the former and current Washington University Wolfram Study Group members for their advice and support. 
Disclosures: Amjad Samara-RELATED: Grant: National Institute on Drug Abuse, Comments: Amjad Samara is a postdoctoral scholar supported by the National Institute on Drug Abuse grant No. 5T32DA007261-27. Heather M. LugarRELATED: Grant: I receive payment via grants from the National Institutes of Health; UNRELATED: Employment: I receive payment via grants from National Institutes of Health; Grants/Grants Pending: I receive payment via grants from the National Institutes of Health. Tamara Hershey-RELATED: Grant: National Institutes of Health*; Support for Travel to Meetings for the Study or Other Purposes: National Institutes of Health*; UNRELATED: Employment: Washington University School of Medicine; Grants/Grants Pending: National Institutes of Health.* *Money paid to the institution.

\section{REFERENCES}

1. Amr S, Heisey $\mathrm{C}$, Zhang $\mathrm{M}$, et al. A homozygous mutation in a novel zinc-finger protein, ERIS, is responsible for Wolfram syndrome 2. Am J Hum Genet 2007;81:673-83 CrossRef Medline

2. Inoue $\mathrm{H}$, Tanizawa $\mathrm{Y}, \mathrm{W}$ asson $\mathrm{J}$, et al. A gene encoding a transmembrane protein is mutated in patients with diabetes mellitus and optic atrophy (Wolfram syndrome). Nat Genet 1998;20:143-48 CrossRef Medline

3. Cagalinec M, Liiv M, Hodurova Z, et al. Role of mitochondrial dynamics in neuronal development: mechanism for Wolfram syndrome. PLoS Biol 2016;14:e1002511 CrossRef Medline

4. Takei D, Ishihara $H$, Yamaguchi $S$, et al. WFS1 protein modulates the free $\mathrm{Ca}(2+)$ concentration in the endoplasmic reticulum. FEBS Lett 2006;580:5635-40 CrossRef Medline

5. Delprat B, Maurice T, Delettre C. Wolfram syndrome: MAMs' connection? Cell Death Dis 2018;9:364 CrossRef Medline

6. Alfaro R, Doty $\mathrm{T}$, Narayanan A, et al. Taste and smell function in Wolfram syndrome. Orphanet J Rare Dis 2020;15:57 CrossRef Medline

7. Rove KO, Vricella GJ, Hershey T, et al. Lower urinary tract dysfunction and associated pons volume in patients with Wolfram syndrome. J Urol 2018;200:1107-13 CrossRef Medline

8. Pickett KA, Duncan RP, Paciorkowski AR, et al; Washington University Wolfram Study Group. Balance impairment in individuals with Wolfram syndrome. Gait Posture 2012;36:619-24 CrossRef Medline

9. Pickett KA, Duncan RP, Hoekel J, et al; Washington University Wolfram Study Group. Early presentation of gait impairment in Wolfram syndrome. Orphanet J Rare Dis 2012;7:92 CrossRef Medline

10. Lugar HM, Koller JM, Rutlin J, et al. Evidence for altered neurodevelopment and neurodegeneration in Wolfram syndrome using longitudinal morphometry. Sci Rep 2019;9:6010 CrossRef Medline

11. Lugar HM, Koller JM, Rutlin J, et al; Washington University Wolfram Syndrome Research Study Group. Neuroimaging evidence of deficient axon myelination in Wolfram syndrome. Sci Rep 2016;6:21167 CrossRef Medline

12. Samara A, Rahn R, Neyman O, et al. Developmental hypomyelination in Wolfram syndrome: new insights from neuroimaging and gene expression analyses. Orphanet J Rare Dis 2019;14:279 CrossRef Medline

13. Gocmen R, Guler E. Teaching NeuroImages: MRI of brain findings of Wolfram (DIDMOAD) syndrome. Neurology 2014;83:e213-14 CrossRef Medline

14. Ito S, Sakakibara R, Hattori T. Wolfram syndrome presenting marked brain MR imaging abnormalities with few neurologic abnormalities. AJNR Am J Neuroradiol 2007;28:305-06 Medline

15. Scolding NJ, Kellar-Wood HF, Shaw C, et al. Wolfram syndrome: hereditary diabetes mellitus with brainstem and optic atrophy. Ann Neurol 1996;39:352-60 CrossRef Medline

16. Bischoff AN, Reiersen AM, Buttlaire A, et al; Washington University Wolfram Syndrome Research Group. Selective cognitive and psychiatric manifestations in Wolfram syndrome. Orphanet $J$ Rare Dis 2015;10:66 CrossRef Medline

17. Marshall BA, Permutt MA, Paciorkowski AR, et al; Washington University Wolfram Study Group. Phenotypic characteristics of early Wolfram syndrome. Orphanet J Rare Dis 2013;8:64 CrossRef Medline
18. Hershey T, Lugar HM, Shimony JS, et al; Washington University Wolfram Study Group. Early brain vulnerability in Wolfram syndrome. PLoS One 2012;7:e40604 CrossRef Medline

19. Harsha KJ, Parameswaran K. Wolfram (DIDMOAD) syndrome with ventral central pontine hyperintensity without brainstem atrophy. Neurol India 2016;64:1310-12 CrossRef Medline

20. Cohen J. A coefficient of agreement for nominal scales. Educational and Psychological Measurement 1960;20:37-46 CrossRef

21. Landis JR, Koch GG. The measurement of observer agreement for categorical data. Biometrics 1977;33:159-74 Medline

22. Bonneville F, Cattin F, Marsot-Dupuch $\mathrm{K}$, et al. T1 signal hyperintensity in the sellar region: spectrum of findings. Radiographics 2006;26:93-113 CrossRef Medline

23. Fujisawa I, Asato R, Kawata M, et al. Hyperintense signal of the posterior pituitary on T1-weighted MR images: an experimental study. J Comput Assist Tomogr 1989;13:371-77 CrossRef Medline

24. Kucharczyk W, Lenkinski RE, Kucharczyk J, et al. The effect of phospholipid vesicles on the NMR relaxation of water: an explanation for the MR appearance of the neurohypophysis? AJNR Am J Neuroradiol 1990;11:693-700 Medline

25. Klyn V, Dekeyzer S, Van Eetvelde R, et al. Presence of the posterior pituitary bright spot sign on MRI in the general population: a comparison between 1.5 and 3T MRI and between 2D-T1 spinecho- and 3D-T1 gradient-echo sequences. Pituitary 2018;21:37983 CrossRef Medline

26. Fujisawa I, Nishimura K, Asato R, et al. Posterior lobe of the pituitary in diabetes insipidus: MR findings. J Comput Assist Tomogr 1987;11:221-25 CrossRef Medline

27. Wang S, Lin K, Xiao D, et al. The relationship between posterior pituitary bright spot on magnetic resonance imaging (MRI) and postoperative diabetes insipidus for pituitary adenoma patients. Med Sci Monit 2018;24:6579-86 CrossRef Medline

28. Elli FM, Ghirardello S, Giavoli C, et al. A new structural rearrangement associated to Wolfram syndrome in a child with a partial phenotype. Gene 2012;509:168-72 CrossRef Medline

29. Shepherd TM, Ades-Aron B, Bruno M, et al. Direct in vivo MRI discrimination of brain stem nuclei and pathways. AJNR Am J Neuroradiol 2020;41:777-84 CrossRef Medline

30. Doherty D, Millen KJ, Barkovich AJ. Midbrain and hindbrain malformations: advances in clinical diagnosis, imaging, and genetics. Lancet Neurol 2013;12:381-93 CrossRef Medline

31. Genis D, Davalos A, Molins A, et al. Wolfram syndrome: a neuropathological study. Acta Neuropathol 1997;93:426-29 CrossRef Medline

32. Shannon P, Becker L, Deck J. Evidence of widespread axonal pathology in Wolfram syndrome. Acta Neuropathol 1999;98:304-08 CrossRef Medline

33. Hilson JB, Merchant SN, Adams JC, et al. Wolfram syndrome: a clinicopathologic correlation. Acta Neuropathol 2009;118:415-28 CrossRef Medline

34. Scaramuzzi M, Kumar P, Peachey N, et al. Evidence of retinal degeneration in Wolfram syndrome. Ophthalmic Genet 2019;40:34-38 CrossRef Medline

35. Hoekel J, Narayanan A, Rutlin J, et al. Visual pathway function and structure in Wolfram syndrome: patient age, variation and progression. BMJ Open Ophth 2018;3:e000081 CrossRef Medline

36. Pakdemirli E, Karabulut N, Bir LS, et al. Cranial magnetic resonance imaging of Wolfram (DIDMOAD) syndrome. Australas Radiol 2005;49:189-91 CrossRef Medline

37. Zhuang FJ, Chen Y, He WB, et al. Prevalence of white matter hyperintensities increases with age. Neural Regen Res 2018;13:2141-46 CrossRef Medline

38. Chaussenot A, Bannwarth S, Rouzier C, et al. Neurologic features and genotype-phenotype correlation in Wolfram syndrome. Ann Neurol 2011;69:501-08 CrossRef Medline

39. Galluzzi P, Filosomi G, Vallone IM, et al. MRI of Wolfram syndrome (DIDMOAD). Neuroradiology 1999;41:729-31 CrossRef Medline 